\title{
Ricardo Palma, precursor de la narrativa no ficcional
}

Roberto Reyes Tarazona 
Escritor y sociólogo. Primer premio del concurso de cuentos "Arguedas", y segundo premio del "COPE" de cuento. Docente en la Facultad de Arquitectura y Urbanismo de la URP. Director de la Revista "Arquitextos". 
En los años sesenta, en Estados Unidos, se empieza a gestar una corriente que se daría a conocer como "Nuevo Periodismo". Los jóvenes periodistas rompen en sus trabajos principios que parecían inconmovibles, como la objetividad y el papel de la prensa como mero instrumento de información; además, el periodista siempre debía mantenerse en un segundo plano, nunca ser protagonista de los hechos.

En este ambiente de inquietudes de renovación del papel y las formas periodísticas, Truman Capote, un reconocido novelista, publica en 1965 A sangre fría, un libro a caballo entre la ficción y el periodismo. En este libro, que gira en torno a un suceso ocurrido en Kansas: el asesinato de la familia Clutter, la captura de los asesinos, su carcelería y el juicio a que son sometidos, Capote presenta los hechos a manera de una novela, pero respetando rigurosamente los hechos. Para ello, utilizó recursos tradicionales de los periodistas: entrevistas, revisión de material forense y policial, evaluación de declaraciones de testigos o gente involucrada de alguna manera en los hechos. Es decir, realizó una exhaustiva investigación que duró varios años (el crimen ocurrió en 1959).

El éxito que tuvo el libro traspasó las fronteras de su país y se convirtió en un "best seller" mundial, que sentó las bases de lo que se denominaría narrativa de no-ficción, o no ficcional. Desde entonces, el tratamiento de hechos reales extraídos del periodismo con un tratamiento literario es para muchos un nuevo género narrativo, el cual ha tenido una larga lista de 
seguidores dentro y fuera de su país, entre los cuales se cuentan los célebres Norman Mailer y Gore Vidal.

Como ocurre a menudo, la gran capacidad de los norteamericanos para promocionar y vender sus productos, sean estos utilitarios, científicos, bélicos o culturales, ha hecho que muchos crean que esta forma es una invención de ellos. Sin embargo, los antecedentes son muy numerosos, y la relación entre realidad y literatura se extiende más allá del periodismo.

Para limitarnos solo a Latinoamérica, podemos mencionar algunos casos de gran repercusión en distintos momentos históricos. Ellos son: Operación Masacre, de Rodolfo Walsh (1957), Juan Pérez Jolote, biografía de un tzoltzil, de Ricardo Pozas (1948), Los sertones, de Euclides da Cunha (1902), y Las tradiciones peruanas, de Ricardo Palma.

Cada uno de estas obras se acerca a la realidad desde disciplinas o ciencias distintas y, por tanto, sus maneras de relacionarse con la literatura son múltiples. El periodismo, en su forma esencial, pretende difundir los hechos de la realidad inmediata, su unidad esencial es la noticia. A partir de ello, se han derivado formas diversas: el reportaje, la crónica, la investigación periodística, etc.

En el caso de Rodolfo Walsh, su interés central por la investigación y denuncia -lo cual a la larga lo llevó a su desaparición y muerte- de un hecho que se quería silenciar, en un contexto político particularmente difícil y riesgoso en su país, lo motivó a escribir un libro que se puede leer como una novela policial. Operación Masacre se convertiría con el tiempo en un modelo de presentación de conspiraciones y acciones políticas ilegales.

La Antropología, ciencia social que estudia el comportamiento del hombre y sus manifestaciones culturales, posee entre 
sus herramientas metodológicas la biografía, la entrevista y la observación participante en pueblos cuya cultura se requiere conocer. La biografía de Juan Pérez Jolote, hecha por Ricardo Pozas, por la riqueza psicológica, la originalidad de su pensamiento y su calidad humana, han convertido el testimonio de este indio proveniente de la región de Chiapas en un texto que, más allá de su condición de material para ser usado en el estudio sobre este grupo, ha trascendido ese papel para convertirse en un libro que puede leerse como una creación novelesca de un personaje singular.

A principios del siglo XX, Euclides Da Cunha, aplicando las teorías científicas de entonces (darwinismo, determinismo), en la geografía humana, la psicología social, la antropología, construyó un informe integral del levantamiento armado del rebelde mesiánico conocido como Antonio Conselheiro, en el desierto de Canudos. No obstante su intención de presentar los sucesos de manera rigurosamente científica, su reconstrucción de los hechos fue tan dramática y cautivante, que este clásico de las letras brasileñas no solo atrajo a miles de lectores sino se constituyó en la base de obras de notables escritores y cineastas, como Mario Vargas Llosa, Guimarães Rosa y Glauber Rocha. $\mathrm{Y}$ es que los hechos narrados por Euclides, como observador enviado por el gobierno brasileño de entonces representan un material que contiene sucesos tan dramáticos, que muchos pasajes superan a la ficción.

Las tradiciones de Ricardo Palma, una amalgama de historia, costumbrismo, ficción y relatos populares, tuvieron una vasta influencia en toda América Latina, constituyendo un nuevo género literario denominado precisamente tradición. Antes de proceder al examen de cómo la ficción se enlaza con la historia y otras expresiones culturales, motivo central de esta ponencia, debemos realizar algunas consideraciones previas. La primera 
de ellas se refiere a la relación entre la realidad y la ficción, entre la verdad y la imaginación y la estética.

La realidad se desprende de los acontecimientos. Estos se producen de una determinada manera; son los hechos tal cual ocurrieron, y su presentación debe ser fiel a ellos, es decir, no debe ser modificada. El problema es que los hechos o acontecimientos no se revelan por sí mismos, sino son los hombres quienes hablan por ellos, quienes los reproducen. Para hacerlo, se requiere de una determinada organización de los elementos intervinientes y un lenguaje adecuado; lo cual demanda técnicas y formas discursivas desprendidas de la disciplina desde la que se encara el asunto. Lo malo es que la manera de ver las cosas está determinada no solo por los conocimientos adquiridos, las teorías que maneja, sino por la postura personal de cada quien.

En el caso de la ficción, las cosas son más flexibles, en la medida que su principal requerimiento es que los hechos parezcan verdad. Es suficiente que den la sensación de ser reales (mímesis), abriéndose a un abanico de posibilidades que van desde lo más parecido a la realidad hasta la fantasía más desaforada, siempre y cuando el lector lo acepte. En este caso, las técnicas y recursos son múltiples y no responden a reglas fijas y estandarizadas, sino son producto de la capacidad creativa del escritor y sus propias motivaciones, conscientes o subconscientes.

La ciencia y las disciplinas que pretenden presentar la realidad de los hechos aspiran a llegar a la verdad objetiva, mas, esta verdad, finalmente, es la versión construida por el mismo hombre. El periodismo y las ciencias suponen posible el que los sujetos releguen su subjetividad en aras de una rigurosa imparcialidad. Para ello, establecen reglas, métodos que tratan de garantizar la objetividad, el respeto a los hechos y, por tanto a la verdad de los acontecimientos. 
Sin embargo, como ya adelantamos, la reconstrucción de la realidad se realiza necesariamente desde una postura o una visión del mundo, que es resultado de la formación intelectual y social del individuo, en la que también intervienen su temperamento y su ideología. De manera que el vínculo entre el hecho objetivo y la subjetividad dan como resultado un texto -un relato, como prefiere considerarlo la semiótica- que puede ser interpretado o leído de diversas maneras. Para mucha gente, incluso en la actualidad, las tradiciones de Palma constituyen la historia real de tal o cual suceso o acción de un personaje.

Por otra parte, no pudiendo ser la realidad inconmovible y unívoca por lo ya mencionado, a este se le debe agregar el hecho de que la realidad humana es una construcción social históricamente determinada. Como es universalmente aceptado ahora, en toda época se lee o interpreta un texto de acuerdo a sus coordenadas espacio-temporales, de manera que lo que parecía una verdad inconmovible en cierto momento pasa a ser cuestionado o rechazado en otro. Como bien dice Susana Reisz de Rivarola, "la inclusión de un fenómeno dado en el ámbito de la realidad o de la irrealidad, varía de una comunidad a otra y de una época a otra". (1979:144)

La reconstrucción de la realidad por la ciencia o la literatura implica, pues, una reproducción de ella por lo general narrándola. Esta narración se plasmará en un texto cuyo autor ha debido realizar un trabajo de organización de los sucesos, el recorte de lo accesorio, la selección y montaje de lo relevante en una secuencia temporal coherente. Por ello, quien intente hacer este trabajo deberá dominar las técnicas y formas discursivas que exige la disciplina o arte bajo el cual pretende expresarse.

En el caso de las ciencias y de la historia, lo que se busca es la generalización de los hechos, presentados de una manera 
distanciada. En cambio, el discurso narrativo literario busca la singularidad de los sucesos, enfocándolos a menudo de cerca y tratando con la misma atención lo insignificante y lo grandioso. Julio Cortázar, en su notable artículo "Algunos aspectos del cuento", relevó, a propósito de sus principios como escritor de cuentos, "el fecundo descubrimiento de Alfred Jarry, para quien el verdadero estudio de la realidad no residía en las leyes sino en las excepciones a esas leyes". En la literatura, lo más valioso son los efectos, la poesía que se pueda encontrar en un objeto, en un giro, en la actitud de un personaje, más que la realidad en sí misma.

Las relaciones entre la narrativa literaria y las diversas formas que exponen hechos bajo reglas científicas o periodísticas, por lo general están delimitadas claramente, aunque en los años sesenta, principalmente debido a la semiótica, comienzan a relativizarse los límites entre los géneros literarios y entre estos y otras expresiones que usan el discurso escrito. De allí que la historia, la novela, la crónica periodística, los testimonios antropológicos son a final de cuentas discursos con diversos niveles de participación de los narradores. Es decir, si bien existen diferencias entre unos y otros, están muy emparentados por el nivel del lenguaje y las formas expositivas.

Cuando aparece la narrativa no ficticia, algunos críticos señalan que las líneas divisorias entre las diversas expresiones narrativas adquieren un nuevo sentido. Antes, según el peso que tuviera una u otra forma de expresión, se la incluía entre alguna ciencia o la literatura. La biografía, tradicionalmente una disciplina que seguía las pautas de la historia, centrada en una investigación sobre la trayectoria vital de un personaje, cuando incorporaba hechos no comprobados, o no respetaba la secuencia cronológica o llenaba vacíos de la vida de un personaje mediante la imaginación, como en las biografías noveladas de André Maurois, dejaba de ser Historia para concederle un lugar en la Literatura. 
No faltaban ocasiones en que se producían tensiones y descalificaciones entre una y otra forma según las interpretaciones realizadas. Si la balanza se inclinaba en uno u otro campo, se la calificaba o incluía en uno u otro campo. Con el género narrativo de no-ficción, singularmente, se alcanzó un equilibrio difícil de alcanzar.

El caso de Ricardo Palma es particularmente complejo, en tanto que incorpora elementos muy diversos en sus tradiciones. José de la Riva Agüero, en su momento, consideró que las tradiciones de Palma eran una conjunción de novela histórica, a lo Walter Scott, con el costumbrismo español. Otros autores posteriores han agregado a ellas elementos de la cultura popular y de la tradición oral. La constante fue su manejo -extremadamente libre- de documentos históricos de diversa índole.

El mismo Palma fue enfatizando a través del tiempo algunos aspectos que definían sus tradiciones. En términos generales, en los primeros conjuntos de tradiciones, el peso de sus aspiraciones de hacer historia de una manera singular -su manera personal- lo hizo valorar de manera enfática las fuentes de las cuales arrancaban sus narraciones. Así, llegó a afirmar: “en el fondo, la tradición no es más que una de las formas que puede revestir la historia, pero sin los escollos de ésta”.

Sin embargo, más adelante, replanteó su postura: "la tradición no es precisamente historia, sino relato popular, y ya se sabe que para mentiroso el pueblo". Y también: “a lo sumo, es un auxiliar de la historia, porque despierta en el lector la curiosidad por investigar en hueso y consultar o beber el agua en mejor fuente".

De cualquier modo, incluso cuando en su madurez había tomado cierta distancia con sus primeros intentos de hacer historia y definitivamente se inclinaba por hacer poesía de 
los hechos del pasado, le asaltaba su apego a las fuentes como elemento importante en la construcción de alguna de sus tradiciones. Así por ejemplo, dijo, defendiendo la "verdad" de una de sus tradiciones:

Dice usted, amigo mío, que con cuatro paliques, dos mentiras y una verdad hilvano una tradición. Pues si en ésta que le dedico hay algo que peque contra el octavo mandamiento, culpa será del cronista agustino que apunta el suceso, y no de su veraz amigo y tocayo.

En otra oportunidad, también en su etapa de madurez, Palma expondrá de otra manera su posición ante la historia y la ficción. Entonces, se animará a dar una serie de consejos sobre cómo escribir una tradición:

... y el que escriba tradiciones, no solo está obligado a darles colorido local, sino que hasta en el lenguaje debe sacrificar, siempre que oportuno lo considere, la pureza clásica del castellano idioma, para poner en boca de sus personajes frases de riguroso provincianismo, y que ya perderá tiempo y trabajo el que se eche a buscarlas en los diccionarios. Cuando se pinta no debe huirse de la naturalidad, por mucho que a veces sea ella ramplona y de mal gusto. Estilo ligero, frase redondeada, sobriedad de las descripciones, rapidez en el relato, presentación de personajes y caracteres en un rasgo de pluma, diálogo sencillo a la par que animado, novela en miniatura, novela homeopática, por decirlo así, eso es lo que en mi concepto ha de ser la Tradición.

Sin embargo, en una u otra etapa, Palma siempre mostró su profundo amor por el pasado, de donde provenía la poesía que no encontraba en el presente. De allí, pues, su interés por la historia. Solo que él también era un creador literario por excelencia, razón por la cual siempre estaba buscando en 
los hechos aquello que fuera encantador, atractivo. Su visión era pues esencialmente interna y propia de un poeta. Para él, el tradicionista tiene que ser poeta y soñador, en cambio, el historiador es el hombre del raciocinio y de las prosaicas realidades. El historiador, siguiendo a Amado Alonso, es aquel que trata de explicar los sucesos observándolos críticamente desde fuera, y cosiéndolos con un hilo de comprensión intelectual. A este respecto, Palma confiesa:

Literariamente tengo la manía de vivir en el pasado, el ayer es siempre poético: es una especie de sol al que apenas se le ven las manchas porque está muy lejos.

Ricardo Palma combina, pues, el documento histórico (crónicas, vidas de santos, libros de viajes, pasquines, testamentos, relatos de misioneros, registro de conventos) con los versos, refranes, dichos, coplas, supersticiones, leyendas, cuentos populares; surgiendo de estas combinaciones una serie de relatos que en su conjunto componen lo que Mariátegui denominó "Crónica novelada”, Y José Riva Agüero, considerando el conjunto de su obra, "historia del Perú novelada".

Las interpretaciones y definiciones de las tradiciones son innumerables por su complejidad y riqueza creativa. Alberto Escobar, en "Tensión, lenguaje y estructura. Las tradiciones peruanas" (1972), llama la atención sobre la singular capacidad de Palma para integrar enfoques aparentemente divergentes. En relación a la realidad y la ficción señala:

“¿Cómo maneja Palma los llamados temas históricos? Hemos rastreados dos formas predilectas. En ciertos casos apela a una fuente escrita: describe el documento o libro, lo glosa, señala su paradero, cómo llegó a él, transcribe algunos párrafos, y lo invoca cada vez que juzga indispensable acogerse a su autoridad 


\section{(...)}

En otras oportunidades, la penetración en la 'historia' elige un curso diverso: es, o casi es, autobiografía o cuando menos testimonio personal, si no del todo, de alguna de las 'partes'. (...)

Ahora bien, aunque no proponemos división tajante, a estas alturas deberíamos admitir que el empleo de una fuente escrita, pomposamente 'histórica', o el uso de noticias espectadas, vividas personalmente o escuchadas, tiene que imponer desemejanzas apreciables entre los textos redactados con una u otra fuente. Nuestra experiencia de lectores nos dice, sin embargo, que no la encontraremos; y esto es de gran significado, pues piénsese que debería existir tal diferencia, siempre que el material 'histórico' fuera lo decisivo en la naturaleza de la Tradición.

De lo expuesto por Escobar pueden seguirse varias líneas de indagación, pero solo queremos resaltar el hecho de apelar a nuestra condición de lectores para zanjar un asunto aparentemente complejo. Y eso es precisamente lo que todos los lectores, independientemente de cómo y para qué se acercan a las tradiciones, encuentran: narraciones siempre enjundiosas, divertidas, intrigantes y redondas estéticamente; narraciones que no han perdido estas cualidades a pesar del tiempo transcurrido. Algo que no consiguió Truman Capote con Plegarias atendidas, su siguiente y último libro, en el que quiso incursionar satíricamente en la sociedad en la que se desenvolvía, sin mucho éxito. Y aunque se le sigue considerando el creador de la narrativa no ficticia, olvidándose que un siglo antes un escritor peruano había empezado una serie de narraciones que son un ejemplo de integración de verdad y ficción, de realidad histórica y recreación imaginaria, el tiempo dará su veredicto final. 


\section{Bibliografía}

CAPOTE, Truman. A sangre fría (1972). Barcelona: Editorial Noguer.

CORTÁZAR, Julio, Algunos aspectos del cuento, Casa de las Américas Año II, Nos. 15-16, Noviembre, 1962 - febrero, 1963, La Habana. Págs. 3-14.

ESCOBAR, "Tensión, lenguaje y estructura. Las tradiciones peruanas" (1971), en: Patio de Letras. Caracas: Monte Ávila Editores,

PALMA, Ricardo. Tradiciones peruanas (1982). Lima: Central Peruana de Publicaciones. Tomos I, II, III, IV.

REITSZ DE RIVAROLA, Susana (1979) "Ficcionalidad, referencia, tipos de ficción literaria”, Lexis, 3, 2, págs. 99-170. 